\title{
Hippuric Acid Crystal Measurement
}

National Cancer Institute

\section{Source}

National Cancer Institute. Hippuric Acid Crystal Measurement. NCI Thesaurus. Code C74754.

The determination of the amount of hippuric acid crystals present in a urine sample. 